\title{
Characterizing Weed Populations in Different Turfgrass Sites throughout the Klang Valley of Western Peninsular Malaysia
}

\begin{abstract}
A field survey was conducted in 2007 to characterize weed populations in different turfgrass sites throughout the Klang Valley of western Peninsular Malaysia. Sites included golf course putting greens, athletic fields, sod farms, and residential lawns. Weeds present in each site were identified and the data were used to calculate frequency, distribution uniformity, density, relative abundance, and community coefficient values for each species. Seventy-nine weed species, belonging to 16 families, were found. The most species were found on residential lawns, and the fewest were found on golf course putting greens; athletic fields and sod farms ranked intermediately. A total of 19 different weed species were classified as major (relative abundance $\geq 15$ ), and abundance rankings varied by turfgrass area. Greater kyllinga had the highest relative abundance values on athletic fields (45.5) and golf course putting greens (71.5), and the second highest value (21.7) on residential lawns. Forked fringerush and annual sedge had the greatest relative abundance values on residential lawns and sod farms, respectively. Cogongrass was reported on $15 \%$ of the residential lawns evaluated. The heterogeneity of weed species composition suggests that control strategies will vary by turfgrass use area. Quantifying weed population dynamics will help researchers delineate integrated weed management strategies to turfgrass managers in Malaysia.
\end{abstract}

Keyword: Relative abundance, weed populations, invasive weeds, noxious weeds 